\title{
Inspirations of Successful Experiences of the Netherlands Flower Industry to the Development of Yunnan Flower Industry
}

\author{
Zhiyu Chen ${ }^{1, \mathrm{a}}$ and Chanjuan Zhao ${ }^{2, \mathrm{~b}, *}$ \\ ${ }^{1}$ College of Economics and Management, Yunnan Agricultural University, Kunming, Yunnan, China \\ ${ }^{2}$ Finance Department, Yunnan Agricultural University, Kunming, Yunnan, China \\ ${ }^{a} 1916544113 @ q q . c o m,{ }^{b} 254861741 @ q q . c o m$ \\ *Corresponding author
}

\begin{abstract}
The flower industry has become one of the important pillar industries in Yunnan province. However, the flower industry still has shortcomings in product quality, variety research and development and innovation ability, flower production scale, standardization and specialization degree, and cold chain logistics system. As the world's traditional flower industry, the Netherlands has provided ample supply of flowers with family farm scale. Unique flower auction patterns makes marketing efficient, fast and perfect cold chain logistics system reduces the loss of product transportation to the lowest, strict floral quality control system ensures high quality of product output, strong product innovation and research and development ability supports the Netherlands flower industry. Learning from the success experience of the flower industry in the Netherlands, the authors provided some suggestions on improving the flower industry development in Yunnan province combining with the actual shortcomings of Yunnan flower industry.
\end{abstract}

Keywords: the Netherlands, Yunnan province, family farm, planting mode, marketing mode, cold chain logistics, quality control, innovation, flower industry

\section{CURRENT SITUATION OF YUNNAN FLOWER INDUSTRY}

\subsection{High Status and Great Market Influence}

At present, Yunnan province has become one of the most important flower producing areas in China and even the world, and the flower industry has become an important force to promote the economic development of Yunnan province.

\subsection{Increasingly Diversified Sales Models}

In recent years, the flower industry sales model in Yunnan province has presented a diversified development trend, mainly carrying out auction trading and wholesale, supplemented by order direct sales and e-commerce.

\section{Problems Existing in Yunnan Flower Industry}

\subsection{Uneven Quality of Flower Products}

As most fresh cut flowers in Yunnan province are produced by individual flower farmers, most of whom have not received professional training in scientific planting technology, the standardization of flower products is not enough and the quality of products is uneven. After farmers harvest flowers from their fields, they screen and auction through Kunming international flower auction and trading center every morning. Only $30 \%$ of high-quality flowers can finally be screened and shipped to the whole country or even other countries at a high price. Nearly 70 percent of the flowers were sold at low prices because they were substandard.

\subsection{Lack of Research and Development and Innovation Ability of Flower Products}

For a long time, more than $90 \%$ of the flowers grown in Yunnan, such as chrysanthemums, roses, carnations and lilies, are imported from abroad. Compared with the scientific research and development capacity of more than 1,000 new varieties in developed countries such as the Netherlands, the flower industry in Yunnan province is currently suffering from backward scientific research, varieties and technologies, leading to problems such as low production efficiency, low product quality and backward varieties.

\subsection{The Scale, Standardization and Specialization of Flower Production are not High}

At present, the fresh cut flowers produced by individual flower farmers account for more than $70 \%$ of the flower industry in Yunnan province. Most of the flower farmers 
have not received professional training, but only plant them with personal experience, which leads to a low degree of standardization and specialization of flower production.

\subsection{Unsound Cold Chain Logistics System}

At present, the flower producers in Yunnan province are mainly individual flower farmers. Because of the cost of capital, the flower farmers cannot have relatively complete preservation equipment, so the flowers are prone to dehydration after harvesting. Because there is no perfect cold chain to guarantee the whole transportation of flowers, the loss of products in the logistics process is over $40 \%$, which has a great impact on the product quality reaching the target market.

\section{EXPERIENCE OF FLOWER INDUSTRY DEVELOPMENT IN THE NETHERLANDS}

\subsection{Large-scale Farming Relying on Family Farms}

The average size of a family farm in the Netherlands is very large. According to the standards of the European Union, Dutch farm production level is relatively high, with a strong competitiveness. Most of the flower farmers in the Netherlands have mastered professional flower planting technologies. Relying on their own family farms, they mainly plant 1 or 2 varieties with large scale, specific varieties and high degree of specialization.

\subsection{Efficient Marketing System Centered on the Auction Market}

The largest proportion of flower products in the Netherlands are from the typical "Dutch auction"-- fair, open, fast and efficient. The flower auction market in the Netherlands has a complete set of comprehensive services, such as flower preservation, packaging, quarantine, customs, transportation and settlement, etc. An efficient flower auction marketing system can provide the freshest cut flowers for flower shops in more than 80 countries and regions. There are 7 flower auction markets all over the country in the Netherlands, and the varieties of flowers from all over the world are auctioned. After the auction, the products are shipped directly to the place designated by the buyer, and the e-ordering system provides information services for the products sold 24 hours a day.

\subsection{Fast and Perfect Cold Chain Logistics System}

The cold chain logistics in the Netherlands is very developed. Most logistics enterprises in the Netherlands have modern refrigeration technology and equipment. Flowers are transported from the origin to the auction market by road reefer containers [1].Thousands of reefer trucks come in and out of the auction market every day, and are shipped to neighboring European countries immediately after the auction. The longer distance is by air. In the Netherlands, airports like Schiphol have special cold storage, which is used to store the flowers that will be shipped to different parts of the world, and ensure that all kinds of flower products can be delivered to flower shops in more than 80 countries and regions in one day [2].

\subsection{Strict Quality Control System for Flower Products}

High quality has always been synonymous with the Dutch flower industry, which is the main reason why the Dutch flower industry is famous in the world. The Dutch government has specially established a set of strict flower quality control system and quality standards, implemented a quality certification system, and adopted product quality credit certification measures to ensure the quality of flower products [3].And to the product that does not auction to go out in flower market, destroy completely, do not sell absolutely low price.

\subsection{Strong Product Innovation and Research and Development Capabilities}

The science and technology of the flower industry in the Netherlands is at the advanced level in the world. In the Netherlands, there are a large number of flower research institutions with reasonable Settings. Each research institution has its own main research direction and can integrate and connect scientific research, promotion, production and market. Flower research institutions are mainly divided into three levels, namely university research institutes, national research institutes and enterprise research institutes, with clear division of labor and mutual cooperation at all levels [4].

\section{DEVELOPMENT DIRECTION AND COUNTERMEASURES OF FLOWER INDUSTRY IN YUNNAN PROVINCE}

\subsection{Promote Standardized and Specialized Production and Strengthen the Construction of Product Quality System}

Product standardization is an important part to ensure the quality of flower products, including the standardization of production technology and product quality. The Netherlands has a very perfect flower quality standard system, products can achieve the highest quality output. In the future, Yunnan flower industry can learn from the experience of the Netherlands to accelerate the formulation and improvement of various standards for the flower industry, including flower product quality standards, export quality standards, flower fertilizer and anther quality standards and other standard systems [5]. 


\subsection{Strengthen the Construction of Innovative Talent Team and Improve the Innovation Ability of Product Research and Development}

Compared with the Netherlands and other countries and regions with developed traditional flower industry, Yunnan province has more advantaged climatic resources and land resources. While making full use of natural resources, Yunnan province should set up a special talent training fund to train a group of professional research-oriented and innovative talents who know and love flowers. The government can support a group of local leading enterprises, encourage them to carry out research and innovation, or encourage enterprises to cooperate with local competent universities to establish a scientific research system and jointly develop flower varieties and seedlings with independent intellectual property rights [6]. We can also regularly send scientific researchers to study and investigate advanced countries such as the Netherlands, or invite senior foreign flower experts to China for training and lectures.

\subsection{Improve the Technical Content of Cold Chain Logistics}

The government should encourage the majority of cold chain logistics companies to carry out research and development of new technologies and new equipment such as cold storage and preservation. Adopt bar code, smart label, rfid and other technologies to gradually improve the technical content of flower packaging. At the same time, actively promote the construction and improvement of flower cold chain logistics system and increase the use ratio of cold chain transport vehicles, so as to establish a complete cold chain logistics system; Encourage the cooperation between the flower production and sales related enterprises, promote the whole flower cold chain transportation.

\subsection{The Government Strengthens Guidance and the Enterprise Clarifies Its Market Positioning}

In the current fierce competition situation of the flower industry, the government and relevant departments should adjust measures to local conditions, strengthen guidance according to the characteristics of the flower industry in Yunnan province, formulate the development plan of the flower industry scientifically, and make reasonable planning and layout of the flower production areas with regional characteristics. As for enterprises, they should carefully analyze and study the market, identify their advantages and disadvantages through studying competitors, find out their market positioning, to base on their own advantages, and focus on developing one or several characteristic products and making them bigger and stronger, so as to avoid repeated and disorderly competition in the flower industry.

\section{REFERENCES}

[1] Lv Peng, Li Linlin, Li Lingyu, et al. Inspiration of Dutch flower logistics on the development of agricultural products logistics in Shandong province [J]. China business theory, 2016 (15) : 106-107.

[2] Zhang Qun . Discussion on the development of Yunnan flower industry in view of the success of Holland flower industry [J]. Western forestry science, 2005 (01) : 79-84. (in Chinese)

[3] Xie Zeli. Study on improving the competitive advantage of Yunnan flower industry [D]. Kunming: Yunnan university of finance and economics, 2008.

[4] Chen Yaohua. development status, existing problems and solutions of Chinese flower industry [D]. Nanjing: Nanjing agricultural university, 2007. (in Chinese with English abstract)

[5] Chen Ming. Research on the development advantages of Yunnan flower industry [D]. Chengdu: southwest university of finance and economics, 2016.

[6] Cheng Da. Research on emerging industries of Yunnan biological resources development [M]. Kunming: Yunnan science and technology press, 2006. 